\title{
Effect of Ethyl Cellulose Content on Release Profile and Pharmacodynamics of Fenoprofen Microparticles
}

\author{
Yomna Abdelkarim Aboueisha1, Shadeed Gad ${ }^{2, \star}$, Waleed Fathy Khalil ${ }^{3}$, Eman Ali Ahmed ${ }^{3}$ Mamdouh $^{1}$ \\ Mostafa Ghorab²
}

${ }^{1}$ Giza Health Affairs Directorate, Ministry of Health, Cairo, EGYPT.

2Department of Pharmaceutics and Industrial Pharmacy, Faculty of Pharmacy, Suez Canal University, Ismailia, EGYPT.

${ }^{3}$ Department of Pharmacology, Faculty of Veterinary Medicine, Suez Canal University, Ismailia, EGYPT.

\begin{abstract}
Introduction: Fenoprofen calcium (FC) is a non-steroidal anti-inflammatory drug and due to its short half-life, high absorption, extensive metabolism and adverse effect, sustained release formulation of FC is desired. Objective: this study was to develop sustained release microcapsules of FC to obtain better drug delivery. Material and Methods: Different formulae of FC microcapsules were prepared by o/w emulsion solvent evaporation method using Ethyl cellulose (EC) in three different ratios. The processed microcapsules were evaluated in-vitro for production yield, entrapment efficiency, micromeritic properties and thermal characteristics and in-vivo for its pharmacodynamics. Results: In-vitro release studies of formulae $\mathrm{H} 1$ and $\mathrm{H} 3$ showed regression coefficient $(\mathrm{r}$ ) value in the Higuchi diffusion model of 0.967 and 0.946 respectively, suggesting diffusion mechanism release from these forms. While marketed capsules and $\mathrm{H} 2$ microcapsules showed regression coefficient value in the zero-order model $(0.985$ and 0.985 respectively), suggesting non-linear release. In-vivo, the carrageenan-induced hind paw edema was induced in rats; the area under the inhibition of inflammation percentage-time curve (AUCO- ${ }_{24}$ ) showed that formula $\mathrm{H} 3$ possesses the highest therapeutic efficiency comparing with marketed capsules followed by formula $\mathrm{H} 1$ and finally $\mathrm{H} 2$. Moreover, in hot plate test in mice, there were highly significant increases in the mean reaction time in groups $\mathrm{H} 2$ and $\mathrm{H} 3$ over the marketed capsule at $12 \mathrm{~h}$ interval $(p<0.001)$. Conclusion: FC loaded EC microcapsule $\mathrm{H} 3$ produced a sustained and effective drug release over a prolonged timeframe that led to greater therapeutic efficacy.
\end{abstract}

Key words: Ethylcellulose, Microencapsulation, Fenoprofen calcium, Sustained release, Pharmacodynamics, Microparticles.

\section{INTRODUCTION}

Patients experiencing chronic diseases and its complications are on the rise. These situations necessitate prolonged therapy resulting in non-compliance. ${ }^{1}$ This problem tends to be severe for drugs with short biological half -lives like FC as these drugs are taken more frequently. FC is a Non-steroidal antiinflammatory drug (NSAID) and highly absorbed $(85 \%)$ on oral administration. It is used for symptomatic relief for some chronic diseases as osteoarthritis, rheumatoid arthritis and for weak to moderate pain. It should be noted that FC is extensively metabolized through first pass effect and its problematic issue is rapid elimination from the plasma $(2-3 \mathrm{~h}) .{ }^{2}$ Because of its short half-life, extensive metabolism, high absorption and adverse effect, sustained release FC formulation is desired.

For a Drug delivery system (DDS), to be an ideal one, there are two main requirements: First, minimize dosing all over the treatment duration and second, the active ingredient being directly sent to the spot of action, so it minimizes side effects. ${ }^{3}$

Modified release DDS is dosage form where the active drugs are directed to a target at a rate and duration designed to
Submission Date: 25-10-2018; Revision Date: 05-01-2019; Accepted Date: 30-03-2019

DOI: 10.5530/ijper.53.3.77 Correspondence: Dr. Shadeed Gad, Department of Pharmaceutics and Industrial Pharmacy, Faculty of Pharmacy, Suez Canal University, Ismailia 41522, EGYPT.

Phone: +201003934422 E-mail: shaded_abdelrahman@pharm.suez.edu.eg

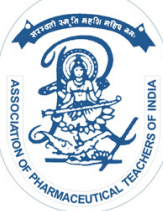

www.ijper.org 
accomplish therapeutic and/or convenience objectives. One of the main modified DDS is sustained/extended release dosage form that provides continuous release of their ingredients at a predetermined/prolonged time. ${ }^{4}$ Microencapsulation means utilizing a thin coating to separate core materials. Techniques for incorporating drugs into polymeric microcapsules have acquired substantial interest. This is attributed to their competence to accomplish a sustained / controlled drug release. The function of microcapsules into diversity therapeutic applications had led to the layout of many different microencapsulation methods, each specifically engineered in view of the requirements of each drug's properties and production setup., ${ }^{5,6}$ Microencapsulation can be benefited in modifying and retarding drug release and improving its absorption. In pharmaceutical sustained release formulations, the advantage of microcapsules lies in the wide distribution throughout the Gastrointestinal tract (GIT). This potentially reduces side effects interrelated to confined build-up of the irritating drugs against the mucosa of the GIT.,

Many different microencapsulation techniques and coating materials can be used. The Emulsion solvent evaporation (ESE) process has been utilized effectively in the formulation of drug microcapsules using different biocompatible polymers. ' EC is a biodegradable, biocompatible, tasteless, odorless, colorless, non-caloric, hydrophobic polymer. The Drug release (DR) from EC depends largely on the pores presented in the hydrophobic microcapsule. Although EC is water insoluble, it can take up water. This is accredited to its hydrogen bonding potential with water. ${ }^{5} \mathrm{EC}$ is the utmost utilized polymer in the preparation of microcapsules for sustained drug delivery because it's biocompatible, versatile and lower cost. ${ }^{10}$ Generally, the single emulsion procedure is most suitable for water-insoluble drugs as steroids, whereas the double emulsion one is considered ideal to encapsulate water-soluble drugs as peptides. The ESE procedure is an economical process that does not prerequisite expensive chemical agents and instruments. ${ }^{11}$

FC conventional oral dosage form can't meet the ideal DDS prerequisites sufficiently. Therefore, this study planned to prepare and evaluate FC microcapsules using EC as coating polymer by O/W ESE process. The formulated FC loaded EC microcapsules have been in-vitro dissolution and in-vivo assayed.

\section{MATERIALS AND METHODS}

Fenoprofen calcium (FC) was received as a gift sample from Western Pharmaceuticals, Al-Obour, Egypt. Ethylcellulose (EC) purchased from Alpha Chemika, Mumbai, India. Ethyl acetate, acetone and ethanol were purchased from El-Nasr for Pharmaceutical Chemicals Co. Egypt. All the chemicals utilized in this investigation were of analytical grade.

\section{Preparation of FC Microcapsules}

Microcapsules were formulated based on o/w ESE by using EC as polymer. The different microcapsules were set by dissolving the EC polymer (In different ratios) and dispersing drug in ethyl-acetate and acetone (Oil phase). This solution was poured gradually in $500 \mathrm{ml}$ solution of distilled water (Aqueous phase) containing $0.4 \mathrm{gm}$ tween 80 , as emulsifying agent, with nonstop stirring on a magnetic stirrer. The resultant mixture was emulsified $5 \mathrm{hr}$. Fine droplets immediately formed from the EC polymer and dispersed drug solution. By solvent evaporation these droplets hardened into rigid microcapsules. The microcapsules were collected by filtration, washed by distilled water to eliminate the excess oil and dried in room temperature and characterized. ${ }^{12}$

\section{Determination of the Production Yields}

The production yields of FC microcapsules were calculated via dividing the actual yield of microcapsules formulated over the theoretical yield (weight of polymer + drug) and multiplied by 100 according to following equation. ${ }^{13}$

$$
\text { Percentage yield }=\frac{(\text { actual yield })}{(\text { weight of polymer }+ \text { drug })} \times 100
$$

\section{Evaluation of the Entrapment Efficiency (EE)}

A quantity of the microcapsules formed equivalent to $5 \mathrm{mg}$ drug was dissolved in ethanol and 0.2 M Phosphate buffer PB ( $\mathrm{pH}$ 6.8) solution using mortar by pestle and vortex for $5 \mathrm{~min}$. The sample was then filtered with Whattman filter paper to obtain clear solution. The absorbance was measured after suitable dilutions with ethanol and 0.2 M PB (pH 6.8) solution at $272 \mathrm{~nm}$ with using ethanol and $0.2 \mathrm{M} \mathrm{PB} \mathrm{(pH} \mathrm{6.8)} \mathrm{solution} \mathrm{as} \mathrm{a} \mathrm{blank.}$ All analysis was done in triplicate, then the average \pm SD was calculated using Microsoft office, 2010. ${ }^{14}$

$$
\text { Entrapment \% }=\frac{\text { actual content }}{\text { theoretical content }} \times 100
$$

\section{Fourier Transforms Infrared Spectrophotometry (FTIR)}

The samples of FC powder and EC alone and the formulated microcapsules were ground and utterly mixed with spectral grade potassium bromide $(\mathrm{KBr})$. The $\mathrm{KBr}$ discs were ready by compressing the powders. The scanning range was from $4000-400 \mathrm{~cm}^{-1}$. IR spectra were 
achieved using an IR spectrophotometer. This was performed in the faculty of pharmacy, Cairo University.

\section{Calorimetric Differential Scanning (DSC)}

DCS scans of FC powder and EC alone and the made microcapsules were done by DSC. The thermal behavior was studied by heating nearly $2 \mathrm{mg}$ of samples in a covered aluminum pans under nitrogen gas flow (30 $\left.\mathrm{ml} . \mathrm{min}^{-1}\right)$ over the temperature range of $\left(0-400^{\circ} \mathrm{C}\right)$ and heating rate of $\left(10^{\circ} \mathrm{C} \mathrm{m^{-1 }}\right)$. This was executed in the faculty of pharmacy, Cairo University.

\section{Densities of Microcapsules}

Both bulk density (Db) and tapped density (Dt) were determined. One gram of microcapsules was put in measuring cylinder (10 $\mathrm{ml}$ capacity). The initial volume was estimated. The cylinder was tapped until no more difference in volume was observed. The following equations were utilized to calculate $\mathrm{Db}$ and $\mathrm{Dt}{ }^{15}$

$\mathrm{Db}=\mathrm{Wt} /$ bulk volume $=\mathrm{Wt} / \mathrm{Vb}$

$\mathrm{Dt}=\mathrm{Wt} / \mathrm{tap}$ volume $-\mathrm{Wt} / \mathrm{Vt}$

\section{Hausner ratio}

It is the ratio between tapped density and bulk density. It provides an idea about the flow characters of powder particles. ${ }^{16}$

Hausner ratio $=\mathrm{Dt} / \mathrm{Db}$

\section{Compressibility Percent (Carr's index)}

The bulk density, size and shape, surface area, moisture content and cohesiveness of materials are indirectly measured by compressibility index. ${ }^{16}$ The compressibility percent of a material can be estimated as.

Compressibility $\%=(\mathrm{Dt}-\mathrm{Db} / \mathrm{Dt}) \times 100$

\section{Angle of Repose}

It was measured by passing the solid microcapsules through a fixed height funnel which was kept at a set height in all tests. Both radius $(r)$ and height $(b)$ of the cone formed were determined. The angle of repose was estimated from the next equation. ${ }^{16}$

$\operatorname{Tan} \theta=\mathrm{h} / \mathrm{r}$

\section{In-vitro Release Study of FC Microcapsules}

Dissolution studies were done by USP dissolution, apparatus II (Paddle type). These studies were done using a USP dissolution tester (Rotating paddle apparatus) at 50 rpm. It was performed at $37 \pm 0.5^{\circ} \mathrm{C}$ in $750 \mathrm{~mL}$ of 0.1 $\mathrm{N} \mathrm{HCl}(\mathrm{pH}$ 1.2). The duration was $2 \mathrm{~h}$ and after that, in PB $(\mathrm{pH}=6.8)$ for a period of $10 \mathrm{~h}$ after changing the $p \mathrm{H}$ from 1.2 to 6.8 via the addition of $250 \mathrm{ml}$ of $0.20 \mathrm{M}$ sodium phosphate. ${ }^{17}$ Marketed capsules and its equivalent in formulated microcapsules ( $\mathrm{H} 1, \mathrm{H} 2$ and $\mathrm{H} 3$ ) were tied at the bottom of the paddle using tea bags. Five- milliliter samples were withdrawn after $0.5,1,1.5,2$, 2.5, 4, 6 and $8 \mathrm{~h}$, the volume was preserved in the vessel by means of new dissolution medium. The samples analyzed for FC content were measured for the absorbance at predetermined $\lambda_{\max } 272 \mathrm{~nm}$. Five milliliters of $\mathrm{PB}$ and ethanol solution (1:1) was put into each of the withdrawn samples then these samples were exposed to spectrophotometric analysis at the predetermined $\lambda_{\text {max }}$ utilizing phosphate buffer and ethanol solution (1:1) as blank. The cumulative percentage which released was calculated. ${ }^{18}$

The experiments were run in triplicates and the mean \pm SD was calculated using Microsoft office excel 2010.

\section{Data Analysis ${ }^{19,20}$}

Three kinetic models, the zero-order release equation (1), Higuchi equation (2) and first order equation (3), were used to manage the in vitro data to discover the equation with the best fit.

$\mathrm{Q}=\mathrm{k} 1 \mathrm{t}(1)$;

$\mathrm{Q}=\mathrm{k} 2(\mathrm{t}) 0.5(2)$;

$\mathrm{Q}=100(1-\mathrm{e}-\mathrm{k} 3 \mathrm{t})(3)$.

Where Q is the release percentage at time t, the $\mathrm{k} 1, \mathrm{k} 2$ and $\mathrm{k} 3$ are the rate constants of zero order, Higuchi and first order model, respectively.

\section{Pharmacodynamics evaluation of FC Microcapsules}

A total of 55 Laboratory animals (25 male Wistar rats weighing 150-200 g and 30 male albino mice weighing 25-30 g), were purchased from laboratory animal house (Faculty of veterinary medicine faculty, Zagazig University) and were used for the comparative pharmacological studies.

These animals stayed in approved plastic cages, with metal mesh lids, at a temperature of $22 \pm 1{ }^{\circ} \mathrm{C}$ and were exposed to a 12-h light dark cycle. They had free entrance to food and water and kept for 1 week to get familiar with the laboratory conditions.

All animals were set apart on the tail with a permanent pen for distinguishing proof. The animals were fasted from food for overnight, maintained in room temperature and each type of animals divided into five groups (Control, standard and 3 Tests).

Each animal was treated with the selected formulae that were picked by the total order. The dose given to each animal of standard and tested groups was equivalent to $100 \mathrm{mg} / \mathrm{kg}$ body weight. ${ }^{21}$

\section{Carrageenan-Induced Hind Paw Edema in Rats for Assessment of Anti-Inflammatory Activity}

Rat hind paw edema method assesses the acute antiinflammatory activity of the formulated microcapsules by injection of an irritant (Phlogistic agent) into the 
tissues of the plantar surface of the hind paw of the rat. ${ }^{22}$ The experiment was executed using one dose level of the standard and test groups. The inflammation was made in rat paws through the injection of $0.1 \mathrm{ml}$ carrageenan suspension ( $1 \%$ in $0.9 \% \mathrm{NaCl}$ solution) in the hind paw sub-plantar tissue.

At the beginning of the test, the thickness of the paws (Baseline) of all test subjects was measured by a Vernier caliper. The first group was considered as a negative control group, injected in the right hind paw sub-plantar tissue by $0.1 \mathrm{ml}$ o carrageenan suspension and served as carrageenan negative control group. While the second group, the positive control group received a marketed FC product dose orally. In the test groups, the three microcapsules were orally administered using the same dose of FC given to the standard group. Meanwhile the left paw was set as a reference. The measurement was recorded at 1, 2, 3, 6, 8, 12 and $24 \mathrm{~h}$ after the medicated formulations administration. ${ }^{23}$ The criteria of comparison were the percent change in paw swelling $(\%$ oedema) in contrast to the baseline measurement. Inhibition $\%$ of the induced edema was considered as an indicator to compare the anti-inflammatory activity with the negative control:

$$
\begin{aligned}
& \text { \% oedema }=\frac{\text { test paw thickness }- \text { initial paw thickness }}{\text { initial paw thickness }} \times 100 \\
& \% \text { inhibition of inflammation }=\frac{\text { control } \% \text { edema }- \text { test } \% \text { edema }}{\text { control } \% \text { edema }} \times 100
\end{aligned}
$$

\section{Hot Plate Method in Mice for Assessment of Analgesic Activity}

The paws of albino mice are very sensitive to heat at a temperature that is not harmful to the skin. The mice respond to heat by jumping, the paws withdrawal and/ or the paws licking ("Hot plate method," 1991). The hot plate method was adopted to evaluate the analgesic activity of the formulated microcapsules. This trial was performed using one dose level of the standard (received a marketed FC product) and test groups. A certain amount equivalent to $(100 \mathrm{mg} / \mathrm{kg}$ of $\mathrm{FC})$ of the prepared microcapsules and marketed capsules as a suspension in $0.1 \%$ sodium lauryl sulphate solution was taken orally to the mice. Each mouse was put in two-liter beaker placed over a hot plate thermostatically controlled at $55 \pm 0.5^{\circ} \mathrm{C}$. When the animals lift and lick their paws or attempt to jump out of the beaker considering the pain threshold is reached. The time taken for the mice to respond in this manner was gotten utilizing a stopwatch and was a reaction time. Recordings were taken after administration at 1, 2, 4, 6, 8 and $12 \mathrm{~h} .{ }^{26}$

\section{Statistical Analysis}

The experimental findings were expressed as mean \pm SD. Statistical analysis was done by one-way analysis of variance ANOVA followed by post hoc test. A level for $p<0.05$ was thought to be statistically significant.

\section{Ethics Approval}

This work was approved by the Faculty of Pharmacy Ethics Committee - Suez Canal University, Ismailia, Egypt under registration number 201810RA1.

\section{RESULTS AND DISCUSSION}

\section{Production Yield and Entrapment Efficiency (EE) of FC Microcapsules}

The yield of microcapsules was observed to be in the range of $71.11-87.33 \%$ of total solid substance used during the microcapsules formulation as displayed in the Table 1. The reduction in the drug (FC) to polymer (EC) ratio decreased the production yield of FC microcapsules. This might be because of an amount of the polymer and drug was stuck on the exterior of stirrer and an amount of the microcapsules adhered to the wall of the container during the microcapsules collection from the external phase. This might explain the low yield in a bit of the batches, this was in agreement with Khairnar et al. who explained the reason for the low yield in some of the batches might be that during the collection of NTG microspheres from the external phase, some of the precipitated polymer was stuck on the surface of stirrer and some of the microspheres were adhered to the wall of the container. ${ }^{27}$

Regarding the percent of FC encapsulated into the polymer, the results discovered that the quantity of EC polymer employed affected the encapsulation of FC significantly as the active principle to the polymer ratio decreased the percent of drug entrapped increases. Table 1 shows the percent of FC entrapped within the formulated different microcapsules ranged from $82.57 \% \pm 2.35$ to $59.69 \% \pm 0.57$.

When the polymer amount increased, the EE increased. This is a result of the increase in the organic phase saturation concentration with the viscosity at a lower drug to polymer ratio that aids in maximizing encapsulation with a homogeneous matrix. As polymer concentration increased matrix forming ability or the binding capability of polymer with active principle also increased. This might be accredited to the maximum quantity of medication get captured in polymeric center producing higher encapsulation in recovered microparticles in lower drug to polymer ratio than that in the higher ratio. ${ }^{28}$ Maji et al. ${ }^{29}$ observed that the active constituent entrapment 
efficiency (\%) of ethyl cellulose microparticles enclosing metformin $\mathrm{HCl}$ prepared by solvent-evaporation technique increased with increasing polymer content, when speed of stirring and concentration of the surfactant were constant, as increasing polymer contents facilitated better coating onto the drug particles.

\section{Fourier Transform Infrared Spectroscopy (FTIR)}

FC, EC and microcapsules formulated (H1, H2 and H3) were exposed to IR analysis to evaluate whether there is an interaction between the drug and polymer (EC). The characteristic $v \mathrm{OH}$ stretching, $v \mathrm{O}-\mathrm{C}=0$ asymmetric and symmetric stretching and $v$ O-C-O stretching of pure drug was observed at $3596 \mathrm{~cm}-1,1558 \mathrm{~cm}-1$ and 1690 cm-1 (Figure 1A). The characteristic peaks confirmed the structure of FC. ${ }^{30}$ The characteristic peaks of FC and EC polymer which included $\mathrm{v}$ C-H stretching bands at $2977 \mathrm{~cm}-1$ and $2923 \mathrm{~cm}-1$ and $\mathrm{v}$ C-H bending at 1379 $\mathrm{cm}-1$ were also present (Figure 1A and B). No significant alteration in the type of peaks in loaded microcapsules denied any strong FC-EC interaction when FC was encapsulated into EC coats by ESE. From this spectral analysis, the $\mathrm{OH}$ and carbonyl groups were affected by possible host/guest hydrogen bond formation. In fact, when a carbonyl group and/ or hydroxyl groups were connected to a hydroxylic compound by hydrogen bonds, the stretching band moved to lower frequency due to a weakening of the carbonyl and hydroxyl radical double bond. ${ }^{31}$ This appears clearly in the spectrum of formula H1 (Figure 1C) where there are a clear shift and fall in the intensity of the characteristic $\mathrm{v}-\mathrm{OH}$ stretching of the hydrate. While, with the increase of EC in micro-

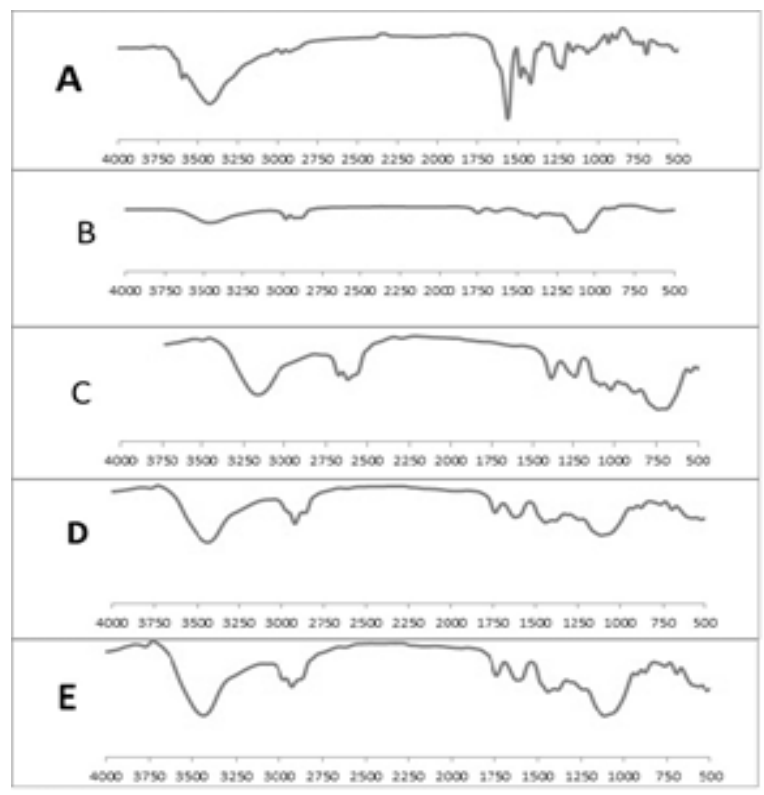

Figure 1: FTIR Spectra of: (A) FC, (B) EC, (C) Formula H1, (D) Formula $\mathrm{H} 2$ and (E) Formula H3. capsules formulated, the characteristic peaks of FC and EC appear clearer in $\mathrm{H} 3$ than $\mathrm{H} 2$ (Figure $1 \mathrm{D}$ and $\mathrm{E}$ ) indicating non-significant polymer and drug interaction. Khairnar et al. ${ }^{27}$ have found that the spectrum of microparticles showed that all characteristic peaks are at the same values as in that of the pure NTG which confirmed the drug. No significant alteration in the type of peaks denied any strong NTG-EC interaction when NTG was encapsulated into EC coats. These findings stated that in different spectra of microcapsules no new peaks appeared which indicate that no chemical bonds were created in the formulated microcapsules.

\section{Thermal Analysis}

\section{Calorimetric Differential Scanning (DSC)}

DSC was carried out to investigate the effect of formulations on thermal behavior of FC. DSC thermograms of unprocessed FC shows an endothermic peak at approximately $94.42^{\circ} \mathrm{C}$ corresponding to a loss of water accompanied by collapse of the crystal structure to a glass, which is in good agreement with the thermal behavior of FC reported in the literature at approximately $94^{\circ} \mathrm{C} \cdot{ }^{30}$ On the other hand, a diffuse endotherm occurs between $50^{\circ} \mathrm{C}$ and $120^{\circ} \mathrm{C}$, correspond to EC was observed in thermograms of the prepared FC microcapsules. Moreover, the peaks of FC unprocessed material disappeared in DSC thermograms of $\mathrm{H} 1$ and, $\mathrm{H} 3$ microcapsules, that perhaps due to uniformly dispersed drug at the molecular level in the microcapsules (Figure 2). These results were favorably compared with the findings reported by Gupta et al. ${ }^{32}$ who stated that

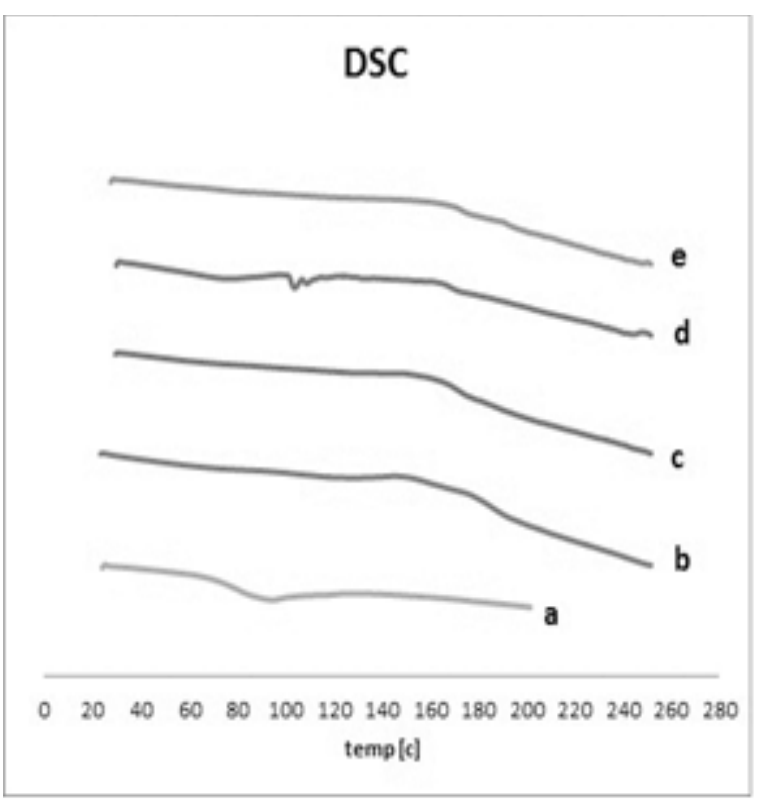

Figure 2: DSC thermograms of: (A) FC, (B) EC, (C) Formula $H 1$, (D) Formula H2 and (E) Formula H3. 
DSC profile of captopril exhibited a sharp endothermic peak at $111^{\circ} \mathrm{C}$, which matches the melting point of the drug, while DSC profile of captopril loaded ethyl cellulose microcapsules did not exhibit endothermic peak at $111^{\circ} \mathrm{C}$.

In another study, Vohra and Patil ${ }^{33}$ conducted DSC study on pure drug (Stavudine), empty and drug-loaded microcapsules. Stavudine exhibits a sharp endothermic peak at $172.88^{\circ} \mathrm{C}$ corresponding to its melting point. The thermogram of microcapsules did not show any drug peak, the authors attributed the absence of drug endothermic peak to uniform dispersion of the drug in the microcapsules.

It was also noted that DSC Thermograms of microspheres $\mathrm{H} 2$ showed a slight endotherm at approximately $103.68^{\circ} \mathrm{C}$ corresponding to the melting endotherm of FC, this may be due to the surface particles of FC on EC microcapsules. This agreed with Dubernet et al. ${ }^{34}$ who found a slight endothermic peak of ibuprofen in ethyl cellulose loaded microcapsules.

It may be concluded that thermal behavior of FC microcapsules suggested that the drug was compatible and was entrapped in the EC microcapsules.

\section{Micromeritics Properties of FC Microcapsule}

Flow characteristics of FC microcapsules were evaluated in terms of angle of repose, tapped density, bulk density and compressibility index. It was found the angles of repose were below $20 \mathrm{oC}$ for all microcapsules indicating free flowing nature of microcapsules. Formulation H3 showed the best value, while formula $\mathrm{H} 1$ showed the least flowability among the formulations, as displayed in the Table 1. Where the values of the bulk densities of formulated microcapsules ranged from $0.186 \mathrm{~g} / \mathrm{ml}$ (H3) to $0.240 \mathrm{~g} / \mathrm{ml}(\mathrm{H} 1)$. In tapped density, the densities ranged from $0.209 \mathrm{~g} / \mathrm{ml}(\mathrm{H} 3)$ to $0.337 \mathrm{~g} / \mathrm{ml}(\mathrm{H} 1)$ indicated that the best ratio belonged to $\mathrm{H} 3$ which was 1.125, while the worst ratio was 1.404 which belonged to H1. The maximum compressibility percent for the tested FC microcapsules was 28.80 for $\mathrm{H} 1$ and the least value was 11.181 for $\mathrm{H} 3$. So, from the previous data, the microencapsulation technique employed in this research produced particles with flowability enhancement over the marketed FC, that is considered relatively good flowability. Bansode et al. ${ }^{35}$ have evaluated the telmisartan microcapsules micromeritic properties in the angle of repose, tapped density, bulk density and compressibility index. It was found the angle of repose in all microcapsules were below 400, indicating free flowing nature of microcapsules.

\section{In-vitro Drug Release}

The dissolution studies of marketed FC capsules and FC formulated microcapsules (H1, H2 and H3) were performed in acidic medium (0.1 N HCl, $\mathrm{pH} 1.2)$ for $2 \mathrm{~h}$ and followed by $6 \mathrm{~h}$ in $\mathrm{PB}$ solution ( $\mathrm{pH}$ 6.8). FC being a weak acidic drug of $\mathrm{pKa} 4.5$, the pure drug dissolved better in $\mathrm{pH} 6.8$ than in $\mathrm{pH} 1.2$. The dissolution in $\mathrm{pH}$ 6.8 was decreased when EC formulated microcapsules were used. The in vitro release profiles of formulation $\mathrm{H} 1$, formulation $\mathrm{H} 2$ and formulation $\mathrm{H} 3$ comparing to marketed FC capsules are displayed in Figure 3. It shows the plot of cumulative percent of drug released as a function of time for different formulations.

The cumulative percentage drug released after $8 \mathrm{~h}$ was $77.13 \%, 51.22 \%, 30.01 \%$ and $40.52 \%$ for marketed FC capsules, H1, H2 and $\mathrm{H} 3$, respectively, which indicates that the formulated microcapsules produced a prolonged drug release over an extended timeframe. From the in vitro drug release profiles, the drug release from microcapsules decreased with the increase in coat material as observed in microcapsules $\mathrm{H} 1$ in comparison with microcapsules (H3). As the coat-core ratio increases from 1:1 to1: 2 , the in vitro drug release decrease, refer to Figure 3. The reason for this could be longer diffusion pathway of the active ingredient in the higher ratio, so the release is retarded. This agrees with Yadav et al. ${ }^{36}$ who prepared Aceclofenac microcapsules with EC and have concluded that EC slows the drug release from prepared microcapsules.

The regression coefficient $(\mathrm{r})$ values for marketed FC capsules and formulations $\mathrm{H} 1$ to $\mathrm{H} 3$ are tabulated in the Table 2. The model that gave higher ' $r$ ' value indicated the most suitable model. The regression coefficient ' $r$ ' values were found to be highest in the zero-order model in marketed FC capsules and formulation H2 (0.985273 and 0.984572 respectively) than any other model, this can be entitled to the saturation of elimination system because of the high concentration, while $\mathrm{H} 1$ and $\mathrm{H} 3$ microcapsules showed highest regression coefficient ' $r$ ' value in the Higuchi diffusion model (0.967984 and 0.945691 respectively), suggesting the drug release by diffusion. The order of release rate observed with all microcapsules was $\mathrm{H} 1>\mathrm{H} 3>\mathrm{H} 2$. Incorporation of varying concentrations of $\mathrm{EC}(\mathrm{H} 1, \mathrm{H} 2$ and $\mathrm{H} 3)$ controlled drug release. This might be credited to decreased penetration of the solvent molecules in the existence of the hydrophobic polymer, causing lower diffusion of the drug from the matrix as indicated by penetration theory. ${ }^{37}$

\section{Pharmacodynamic Studies of FC Microcapsules}

\section{Anti-Inflammatory Activity using Carrageenan- Induced Hind Paw Edema in Rats}

The anti-inflammatory effect of formulated microcapsules (H1, H2 and H3) that contain $100 \mathrm{mg} / \mathrm{kg}$ equivalent $\mathrm{FC}$ was monitored and contrasted with the 


\begin{tabular}{|c|c|c|c|c|c|c|c|}
\hline \multicolumn{7}{|c|}{ Table1: Micromeritics Properties of FC Microcapsules and Commercial FC. } \\
\hline Formula & $\begin{array}{c}\text { Yield \% } \\
\pm \text { SD }\end{array}$ & $\begin{array}{c}\text { Entrapment } \\
\text { efficiency } \\
\pm \text { SD } \%\end{array}$ & $\begin{array}{c}\text { Angle of } \\
\text { repose } \pm \text { SD }\end{array}$ & $\begin{array}{c}\text { Hausne ratio } \\
\pm \text { SD }\end{array}$ & $\begin{array}{c}\text { Compressibility } \\
\text { index } \pm S D\end{array}$ & $\begin{array}{c}\text { Bulk density } \\
\pm S D\end{array}$ & $\begin{array}{c}\text { Tapped } \\
\text { density } \\
\pm S D\end{array}$ \\
\hline H1 & $87.33 \% \pm 0.12$ & $59.69 \pm 0.57$ & $19.97 \pm 0.325$ & $1.404 \pm 0.007$ & $28.80 \pm 0.402$ & $0.240 \pm 0.003$ & $0.337 \pm 0.006$ \\
\hline H2 & $74.67 \% \pm 0.1$ & $61.06 \pm 0.38$ & $\begin{array}{c}17.016 \pm \\
0.144\end{array}$ & $1.23 \pm 0.0035$ & $18.883 \pm 0.230$ & $0.209 \pm 0.002$ & $0.258 \pm 0.003$ \\
\hline H3 & $71.11 \% \pm 0.2$ & $82.57 \pm 2.35$ & $15.73 \pm 0.21$ & $1.125 \pm 0.001$ & $11.181 \pm 0.121$ & $0.186 \pm 0.002$ & $0.209 \pm 0.002$ \\
\hline Market FC & 100 & 100 & $23.5 \pm 0.5$ & $1.480 \pm 0.006$ & $32.43 \pm 0.305$ & $0.162 \pm 0.001$ & $0.240 \pm 0.003$ \\
\hline
\end{tabular}

\begin{tabular}{|c|c|c|c|}
\hline \multirow{2}{*}{ Table 2: In vitro Release Kinetics Studies of FC Microcapsules and Commercial FC. } \\
\hline \multirow{2}{*}{ Formulation } & \multicolumn{3}{|c|}{ Regression coefficient (r) values } \\
\cline { 2 - 4 } & Zero order & First order & Higuchi \\
\hline Commercial FC & 0.985273 & 0.940804 & 0.968214 \\
\hline H1 & 0.960056 & 0.805711 & 0.967984 \\
\hline H2 & 0.984572 & 0.711208 & 0.974779 \\
\hline H3 & 0.930258 & 0.768802 & 0.945691 \\
\hline
\end{tabular}

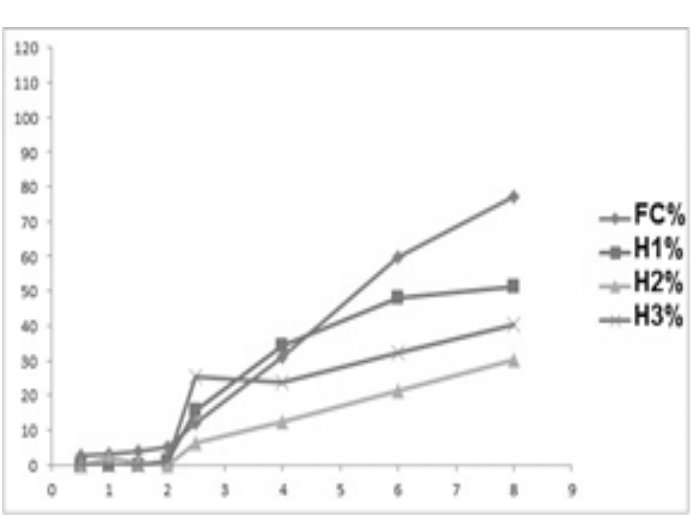

Figure 3: In vitro Dissolution Profile of Commercial FC and FC Microcapsules ( $\mathrm{H} 1$ to $\mathrm{H} 3$ ) in $0.1 \mathrm{~N} \mathrm{HCl}(\mathrm{pH} \mathrm{1.2})$ for $2 \mathrm{~h}$, then in Phosphate Buffer (pH 6.8) for $6 \mathrm{~h}$.

marketed FC capsules that served as a positive control. The mean percentage change in rat paw volume $(\%$ edema) and the percentage inhibition of inflammation post consuming the all formulae and the marketed FC capsules were valued and the pharmacodynamics parameters as in maximum percentage of inhibition $(\%$ $\left.\mathrm{Inh}_{\max }\right), T_{\max }$ and $\left(\mathrm{AUC}_{0-24 \mathrm{~h}}\right)$ for the mean value of each tested group were calculated and all these numbers are displayed in Table 3. The percentages of inhibition of inflammation-time profiles of all formulae were quite different.

It was found that marketed FC capsules (Positive control) showed the maximum percent of inhibition after $2 \mathrm{~h}$ of injection of the inflammatory agent $(75.29 \%)$ followed by a decline in percentage afterward. However, for $\mathrm{H} 1, \mathrm{H} 2$ and $\mathrm{H} 3$, were $68.24 \%, 38.82 \%$ and $40 \%$ respectively and followed by a rise in the percent of inhibition afterward. Formula H1 showed the maximum percent of inhibition $(71.26 \%)$ after $3 \mathrm{~h}$ with maintaining a percent of inhibition above $60 \%$ until $6 \mathrm{~h}$ after the inflammatory agent was introduced. On the other hand, $\mathrm{H} 2$ showed the most inhibition at $24 \mathrm{~h}$ and its percent of inhibition never exceeded $65 \%$, while $\mathrm{H} 3$ showed at $12 \mathrm{~h}$ a maximum inhibition of edema $(80.36 \%)$. It was detected a fall in the \% of inhibition of carrageenaninduced rat paw edema observed after $6 \mathrm{~h}$ of marketed FC capsules post administration, while formulation $\mathrm{H} 3$ showed an increase in the percentage of inhibition $6 \mathrm{~h}$ after consuming the inflammatory agent.

Moreover, latter formula showed higher percentages of inhibition of the rat paw edema induced by carrageenan after both 12 and 24h. This can be inferred to be because of prolonged release effect of EC microcapsules and in turn, indicates its better anti-inflammatory effect $12 \mathrm{~h}$ post-administration compared to marketed FC capsules.

Concerning the area under the inhibition of inflammation percentage -time curve $\left(\mathrm{AUC}_{0-24}\right)$ using the trapezoidal rule as a measurement of therapeutic effectiveness, formula $\mathrm{H} 3$ possesses the highest therapeutic effect as compared with marketed FC capsules followed by formula $\mathrm{H} 1$ and finally $\mathrm{H} 2$. The $\mathrm{T}_{\max }$ value of formulation $\mathrm{H} 3$ showed a higher value at $12 \mathrm{~h}$ compared to $\mathrm{T}_{\max }$ value of marketed FC capsules at $2 \mathrm{~h}$.

This result points that $\mathrm{H} 3$ possesses a slower onset of action and strongest anti-inflammatory effect $12 \mathrm{~h}$ after administration compared to marketed FC capsules. These finding states that the microcapsule $\mathrm{H} 3$ expresses 
Table 3: Anti-inflammatory Activity of Commercial FC and the Tested Formula of FC Microcapsules using Carrageenan-Induced Hind Paw Edema in Rats as Percent of Edema Inhibition.

\begin{tabular}{|c|c|c|c|c|}
\hline Time (h) & Commercial FC & H1 & H2 & H3 \\
\hline 1 & $50.51 \% \pm 0.14$ & $50.51 \% \pm 0.23$ & $13.13 \% \pm 0.09$ & $24.24 \% \pm 0.21$ \\
\hline 2 & $75.29 \% \pm 0.7$ & $68.24 \% \pm 0.7$ & $38.82 \% \pm 0.4$ & $40.00 \% \pm 0.4$ \\
\hline 3 & $58.62 \% \pm 0.13$ & $71.26 \% \pm 0.12$ & $49.43 \% \pm 0.16$ & $33.33 \% \pm 0.21$ \\
\hline 6 & $40.28 \% \pm 0.12$ & $64.17 \% \pm 0.16$ & $62.50 \% \pm 0.29$ & $52.78 \% \pm 0.11$ \\
\hline 8 & $20.78 \% \pm 0.15$ & $48.05 \% \pm 0.27$ & $61.04 \% \pm 0.12$ & $70.13 \% \pm 0.18$ \\
\hline 12 & $16.07 \% \pm 0.13$ & $58.93 \% \pm 0.32$ & $23.21 \% \pm 0.21$ & $80.36 \% \pm 0.31$ \\
\hline 24 & $10.71 \% \pm 0.16$ & $50.00 \% \pm 0.55$ & $64.29 \% \pm 0.45$ & $50.00 \% \pm 0.40$ \\
\hline UUC $_{(0-24 h)}(\%$ inh) & 573.68 & 1312.02 & 1055.04 & 1403.98 \\
\hline Inh. $\max (\%)^{24}$ & $75.29 \%$ & $71.26 \%$ & $64.29 \%$ & $80.36 \%$ \\
\hline$T_{\max }(\mathrm{h})$ & 2 & 3 & 24 & 12 \\
\hline
\end{tabular}

a sustained effect, which can be recognized as EC based microencapsulated DDS. ${ }^{38}$

One-way ANOVA followed by post-hoc test was executed to determine the significant variance between the percentage of inhibition of edema of the tested formulae and marketed FC capsules using Microsoft excel $2010^{\circledR}$ software. The results revealed a significant variance between the percentage inhibition of edema of prepared formulations (H1, $\mathrm{H} 2$ and $\mathrm{H} 3)$ and marketed FC Capsules at all-time intervals till $12 \mathrm{~h}(p<0.05)$ and no significance at $24 \mathrm{~h}$. This is a result to the release of edema after $24 \mathrm{~h}$. In case of marketed FC capsules, there was a significant variation between the percentage change in rat paw volume of the marketed product in contrast with the negative control group from $1 \mathrm{~h}$ interval till $6 \mathrm{~h}$ interval $(p<0.05)$.

While there was a highly significant difference between the percentage change in rat paw volume of $\mathrm{H} 1$ and $\mathrm{H} 3$ compared to the negative control group from $2 \mathrm{~h}$ interval till $12 \mathrm{~h}$ interval $(p<0.001)$. Compared to the positive (Marketed FC capsules) group, H1 and H2 showed a highly significant difference in the percentage change in rat paw volume after $6 \mathrm{~h}$ interval till $12 \mathrm{~h}(p<0.001)$.

In case of $\mathrm{H} 2$ there is a highly significant difference among the percentage change in the volume of rat paw of $\mathrm{H} 2$ compared to the control group from $2 \mathrm{~h}$ interval till $8 \mathrm{~h}$ interval $(\phi<0.001)$ and a highly significant difference among the rat paw volume change percent of $\mathrm{H} 2$ and with the marketed product group after $6 \mathrm{~h}$ interval till $8 \mathrm{~h}$ interval $(p<0.001)$. These results prove that the formulae $\mathrm{H} 1$ and $\mathrm{H} 3$ provide an anti-inflammatory action that is more effective than the marketed drug and a sustained action for at least $12 \mathrm{~h}$.

\section{Hot Plate Test (The Analgesic Effect)}

The analgesic activity of FC prepared in form of microcapsules was studied by hot plate method compared with the marketed FC capsules that served as standard. The Mean reaction time (MRT) in mice was calculated and the outcomes are presented in Table 4.

It is observed that, standard group which treated with FC capsules produced the maximum increase in MRT $(41 \mathrm{sec})$ at $6 \mathrm{~h}$. While, the group treated with microcapsule $\mathrm{H} 1$ produced the maximum increase in MRT (39 sec) at $4 \mathrm{~h}$, the group treated with microcapsules $\mathrm{H} 2$ produced the maximum increase in MRT $(38.7 \mathrm{sec})$ at 8 $h$ and the group treated with microcapsule $\mathrm{H} 3$ produced a maximum increase in MRT $(44 \mathrm{sec})$ at $6 \mathrm{~h}$.

The ANOVA analysis concerning the analgesic effect of FC microcapsules and marketed FC capsules using hot plate method was done and showed that marketed FC capsules and all the examined formulations significantly increase MRT compared to negative control $(p<0.05)$. Where marketed FC Capsules significantly increase MRT compared to control from $1 \mathrm{~h}$ interval till $6 \mathrm{~h}$ interval then became insignificant after that.

In case of the formulated microcapsules, $\mathrm{H} 1$ showed a highly significant increase in MRT in relation to control $(p<0.001)$ from $1 \mathrm{~h}$ interval till $4 \mathrm{~h}$ interval as the marketed FC Capsules. The results of MRT in H2 and H3 were significant compared with that of control from $2 \mathrm{~h}$ interval and lasted till $12 \mathrm{~h}$ interval $(p<0.05)$.

Moreover, these two formulae in comparing to marketed FC capsules there was a significant increase in MRT at an $8 \mathrm{~h}$ interval $(p<0.05)$ and a highly significant rise in mean reaction time at a $12 \mathrm{~h}$ interval $(p<0.001)$. These findings confirmed the sustained analgesic action of $\mathrm{H} 2$ and formula $\mathrm{H} 3$ formulations.

The longer the MRT, the longer the extent of analgesic activity of FC microcapsules ( $\mathrm{H} 2$ and $\mathrm{H} 3$ ), this may be resulted from the slow and prolonged release of entrapped drug in microcapsules in contrast with the marketed product as the drug release retarded by 
Table 4: Analgesic Activity of Commercial FC and the Tested Formula of FC Microcapsules using Hot Plate Test as Mean Reaction Time in sec.

\begin{tabular}{|c|c|c|c|c|c|}
\hline Time & Control & Commercial FC & H1 & H2 & H3 \\
\hline 1 & 15.7 & 31.3 & 32.3 & 22.8 & 25.8 \\
\hline 2 & 13.2 & 40.3 & 26.3 & 30.5 & 29.0 \\
\hline 4 & 15.2 & 34.5 & 39.0 & 34.3 & 31.3 \\
\hline 6 & 13.7 & 41.0 & 33.5 & 38.7 & 34.0 \\
\hline 8 & 15.3 & 35.8 & 31.0 & 33.8 & 33.7 \\
\hline 12 & 14.8 & 18.8 & 20.3 & 38.7 & 44 \\
\hline Mean reaction time $_{\max }$ & 15.7 & 41 & 39 & 8 & 6 \\
\hline$T_{\max }$ & 1 & 6 & 4 & & \\
\hline
\end{tabular}

the polymer coat. After carrying out the analgesic test, the studied formulation $\mathrm{H} 2$ and formulation $\mathrm{H} 3$ have a decent and sustained analgesic effect. After carrying out pharmacodynamic studies, H3 possessed a highest sustained action in both analgesic and anti-inflammatory..

\section{CONCLUSION}

Development of FC loaded ethyl cellulose microcapsules represents a promising sustained release drug delivery system that offers prolonged and uniform drug release. The formulation $\mathrm{H} 3$ (1:2 drug to polymer ratio) is the most fit one for extended drug delivery among other formulations. The current data proved that formulation $\mathrm{H} 3$ provided the best formulation in physical, in-vitro and in-vivo results. This formula showed best entrapment efficiency, highest followability and no interaction between the EC coat and FC as presented in the FTIR, DSC. In terms in-vitro and in-vivo evaluation H3 proved an effective and drug release sustained over $12 \mathrm{~h}$ timeframe suggesting decreasing the frequency of daily dosing.

\section{ACKNOWLEDGEMENT}

Authors are thankful to Western Pharmaceuticals, AlObour, Egypt for providing gift sample of Fenoprofen calcium and Faculties of Pharmacy and Veterinary Medicine, Suez Canal University for support and facilities.

\section{CONFLICT OF INTEREST}

The authors declare no conflict of interest.

\section{ABBREVIATIONS}

FC: Fenoprofen calcium; EC: Ethyl cellulose; DDS: Drug delivery system; NSAID: Non-steroidail antiinflammatory drug; GIT: Gastrointestinal tract; DR: Drug release; ESE: Emulsion solvent evaporation; KBr: Potassium Bromide; FTIR: Fourier Transmission Infrared; DSC: Differential scanning calorimetry; Db:
Bulk density; Dt: Tapped density; Wt: Weight; Vb: Bulk volume; Vt: Tapped volume; PB: Phosphate buffer; USP: United States Pharmacopeia; $\mathbf{H C l}$ : Hydrochloric acid; NaCl: Sodium chloride; NTG: Nateglinide; EE: Entrapment efficiency; MRT: Mean reaction time; SD: Standard deviation.

\section{REFERENCES}

1. Yamada T, Onishi H, Machida Y. Sustained release ketoprofen microparticles with ethyl cellulose and carboxy methylethyl cellulose. J Control Rel. 2001;75(3):271-82.

2. Lemke TL, Williams DA, Roche VF, Zito SW. Foye's principles of medicinal chemistry. $7^{\text {th }}$ ed. Year. 2012;1013.

3. Diab R, Canilho N, Pavel IA, Haffner FB, Girardon M, Pasc A. Silica-based systems for oral delivery of drugs, macromolecules and cells. Advances in Colloid and Interface Science. 2017;249:346-62.

4. Qiu Y, Lee PI. Rational Design of Oral Modified-Release Drug Delivery Systems. Developing solid oral dosage forms, Pharmaceutical Theory and Practice. $2^{\text {nd }}$ ed. London: Academic. 2017;519.

5. Khan IU, Ranjha NM, Mehmood HQ. Development of ethyl cellulosepolyethylene glycol and ethyl cellulose-polyvinyl pyrrolidone blend oral microspheres of ibuprofen. Drug Delivery Science and Technology. 2010;20(6):439-44.

6. Chirani S, Lebig MO, Bouameur S, Mouffok M, Naziha CN, et al. Elaboration of Microspheres' Capsules Based on Ethylcellulose and Synthesized Poly (Butylsuccinate) as Biodegradable Matrices for Drug Delivery of an Antithyroidian Agent. IJPER. 2017;51(2S):S79-90.

7. Li SP, Kowalski CR, Feld KM, Grim WM. Recent advances in Microencapsulation Technology and equipment. Drug Dev Ind Pharm. 1988;14(2-3):353-76.

8. Banabid W, Djerboua F, Maiza A, El Bahri Z, Baitiche M. Optimization and In-vitro Evaluation of Poly (lactic acid) /Mesalazine Microspheres as Drug Carriers. IJPER. 2017;51(2S):S46-53.

9. Song M, Li N, Sun S, Tiedt LR, Liebenberg W, DeVilliers MM. Effect of Viscosity and Concentration of Wall Former, Emulsifier and Pore-Inducer on the Properties of Amoxicillin Microcapsules Prepared by Emulsion Solvent Evaporation. II Farmaco. 2005;60(3):261-7.

10. Saravanan M, Anupama B. Development and evaluation of ethylcellulose floating microspheres loaded with ranitidine hydrochloride by novel solvent evaporation-matrix erosion method. Carbohydrate Polymers. 2011;85(3):5928.

11. Makadia HK, Siegel SJ. Poly lactic-co-glycolic acid (PLGA) as biodegradable controlled drug delivery carrier. Polymers. 2011;3(3):1377-97.

12. Petal B, Modi V, Petal K, Petal M. Preparation and evaluation of ethyl cellulose microspheres prepared by emulsification- solvent evaporation method. IJRMP. 2012;1(1):82-91. 
13. Venkatesan P, Manavalan R, Valliappan K. Preparation and evaluation of sustained release loxoprofen loaded microspheres. Journal of Basic and Clinical Pharmacy. 2011;2(3):159-62.

14. Asad M, Bashir S, Mahmood T, Nazir I, Imran M, Karim S, et al. Fabrication and characterization of gliclazide loaded microcapsules. Braz Arch Biol Technol. 2014;57(6):874-81.

15. Tayade PT, Kale RD. Encapsulation of water- insoluble drugs by a cross- linking technique: Effect of process and formulation variables on encapsulation efficiency, particle size and In vitro dissolution rate. AAPS Pharm Sci. 2004;6(1):1-8.

16. US Pharmacopeia 29: Powder flow. 2006. Available from: www.pharmacopeia. cn/v29240/usp29nf24s0_c1174.html

17. United States Pharmacopeia 30: NF 25; US pharmacopeial Convention: Twinbrook Parkway, Rockville, MD, USA. 2007.

18. Khan KA. The concept of dissolution efficiency. J Pharm Pharmacol. 1975;27(1):48-9.

19. James E, Singh G, Larry L, Vinod P. Method to compare dissolution profiles and a rationale for wide dissolution specification for metoprolol tartrate tablets. J Pharm Sci. 1997;86(6):690-700.

20. Huang YB, Tsai YH, Sung CH, Chang JS, Tsai MJ, Wu PC. Sustained-release dosage form of nicardipine hydrochloride prepared by Eudragit and enteric polymer: In vitro and In vivo study. Journal of Food and Drug Analysis. 2006;14(4):334-9.

21. Brogden RN, Pinder RM, Speight TM, Avery GS. Fenoprofen: A Review of its pharmacological properties and therapeutic efficacy in rheumatic diseases. Drugs. 1977;13(4):241-65.

22. Winter CA, Risley EA, Nuss GW. Carrageenin induced oedema in hind paw of the rats as an assay for anti-inflammatory drugs. Proc Soc Exp Biol Med. 1962;111(3):544.

23. Ammar HO, Makram TS, Makram Sh. Effect of polymers on the physicochemical properties and biological performance of fenoprofen calcium dihydrate-Triacetyl-Cyclodextrin Complex. Pharmaceutics. 2017;9(3):23.

24. Lanhers MC, Fleurentin J, Mortier F, Vinche A, Younosm C. Anti-inflammatory and analgesic effects of an aqueous extract of Harpagophytum procumbens. Planta Med. 1992;58(02):117-23.

25. Baboota S, Shakeel F, Ahuja A, Ali J, Shafiq S. Design, development and evaluation of novel nano-emulsion formulations for transdermal potential of celecoxib. Acta Pharm. 2007;57(3):315-32.
26. Gupta M, Mazumder UK, Kumar RS, Kumar TS. Studies on antiinflammatory, analgesic and antipyretic properties of methanol extract of caesalpiniabonducella leaves in experimental animal models. Iran J pharm Therap. 2003;2(2):30-4.

27. Khairnar G, Mokale V, Naik J. Formulation and development of nateglinide loaded sustained release ethylcellulose microspheres by O/W solvent emulsification technique. J of Pharmaceutical Investigation. 2014;44(6):41122.

28. Pandav S, Naik J. Preparation and In vitro evaluation of ethylcellulose and polymethacrylate resins loaded microparticles containing hydrophilic drug. Journal of Pharmaceutics. 2014;2014:1-5.

29. Maji R, Ray S, Das B, Nayak AK. Ethylcellulose microparticles containing metformin $\mathrm{HCl}$ by emulsification-solvent evaporation technique: Effect of formulation variables. ISRN Polymer Sci. 2012;2012:1-7.

30. Ward CK, Schirmer RE. Fenoprofen Calcium. Analytical Profiles of Drug Substances. 1977;6:161-82.

31. Otero-Espinar FJ, Anguiano-Jgea S, Garcia-Gonazalez N, Vila-Jato JL, Blanco-Mendez J. Inclusion complexes of beta-cyclodextrin with flurbiprofen, ketoprofen and naproxen. Int J Pharm. 1992;79:149-57.

32. Gupta R, Shanthi CN, Mahato AK. Characterization of captopril-ethylcellulose microspheres. Int J Drug Dev and Res. 2010;2(2):394-8.

33. Vohra SY, Patil CC. Development and characterization of stavudine microspheres prepared using different polymers. Journal of Pharmacy Research. 2009;2(3):953-7.

34. Dubernet C, Rouland JC, Benoit JP. Ibuprofen-loaded ethylcellulose microspheres: Analysis of the Matrix Structure by Thermal Analysis. Journal of Pharmaceutical Sciences. 1991;80(11):1029-33.

35. Bansode SD, Kasture VS, Pawar SS, Kasture SB. Formulation and evaluation of telmisartan microspheres by emulsion solvent evaporation technique. J of Applied Pharmaceutical Science. 2012;2(10):113-6.

36. Yadav AV, Shete AS, Dabke AP, Shinde VR. Formulation and In-vitro evaluation of aceclofenac microcapsules. International Journal of Pharm Tech Research. 2009;1(2):135-8.

37. Enayatifard R, Saeedi M, Akbari J, Tabatabaee YH. Effect of Hydroxypropyl Methylcellulose and Ethyl Cellulose Content on Release Profile and Kinetics of Diltiazem $\mathrm{HCl}$ from Matrices. Tropical J Pharmaceutical Research. 2009;8(5):425-32.

38. Murtaza GH. Ethylcellulose microparticles: a review. Acta Pol Pharm. 2012;69(1):11-22.

\section{SUMMARY}

Fenoprofen Calcium is a non-steroidal anti-inflammatory drug and due to its short half-life, high absorption, extensive metabolism and adverse effect, sustained release formulation of FC is desired. This study was to develop sustained release microcapsules of FC to obtained better drug delivery. The formulated microcapsules have shown a good yield, higher entrapment efficiency with the increase of polymer content, better flow properties than unformulated FC and FTIR and DSC assay results shown no new peaks in IR spectra or DSC thermograms, thus no chemical interaction between the FC and EC. The formulated FC loaded EC microcapsules have been in vitro dissolution and in vivo assayed. In vitro release studies of formulae $\mathrm{H} 1$ and $\mathrm{H} 3$ showed regression coefficient ' $r$ ' value in the Higuchi diffusion model (0.967 and 0.946 respectively), suggesting the drug release from these forms follow diffusion mechanism, while marketed capsules and $\mathrm{H} 2$ microcapsules showed regression coefficient ' $r$ ' value in the zero-order model ( 0.985 and 0.985 respectively), suggesting nonlinear release. In vivo, Carrageenan-induced hind paw edema in rats, the area under the inhibition of inflammation percentage-time curve $\left(\mathrm{AUC}_{0-24}\right.$ ) showed that formula $\mathrm{H} 3$ possesses the highest therapeutic efficiency comparing with marketed capsules followed by formula H1 and finally H2. Moreover, in hot plate test in mice, a highly significant increase in mean reaction time in groups $\mathrm{H} 2$ and $\mathrm{H} 3$ over marketed capsule at $12 \mathrm{~h}$ interval $(p<0.001)$. The current data proved that formulation H3 (1:2 drug to polymer ratio) provided the best formulation in physical, in vitro and in vivo results. FC loaded EC microcapsule $\mathrm{H} 3$ produced a sustained and effective drug release over a prolonged timeframe that will lead to greater therapeutic efficacy. 
PICTORIAL ABSTRACT
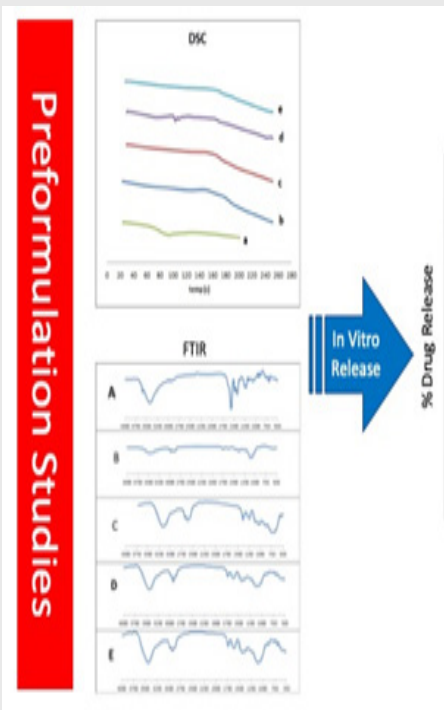

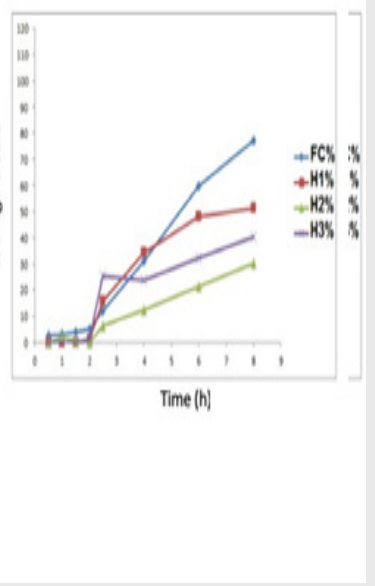

\section{ABOUT AUTHORS}

Prof. Mamdouh Ghourab, currently working as Professor of Pharmaceutics, Faculty of Pharmacy, Suez Canal University, Ismailia, Egypt. He has more than 20 years of Teaching and Research experience. He has published more than 30 research papers in reputed peer review National and International journals. He has filed 2 Egyptian Patents. He has guided more than 20 MSC and PhD students for their research Dissertation. He is reviewer in various National and International peer review journals. He has attended several National and International Conferences/ Seminars

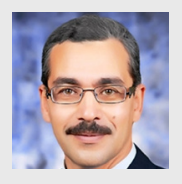

Prof. Waleed Fathy Khalil, currently working as Professor of Pharmacology, Department of Pharmacology, Veterinary Medicine Faculty, Suez Canal University. Ismailia, Egypt. He worked as visiting researcher in Pharmacology Lab, Veterinary Medicine Department, Tokyo University of Agriculture and Technology, Japan (1999-2001, 2005-2010). Out of the 21 published articles, 14 are published in reputable international journals. Total citation is 73 and h-index is 5 . He is a reviewer and editor in 11 journals

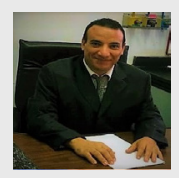

Dr. Shadeed Gad Currently working as Associate Professor and Head, Department of Pharmaceutics, Faculty of Pharmacy, Suez Canal University, Ismailia, Egypt. He has 20 years of Teaching and Research experience. He has published more than 15 research in reputed peer review journals. He has guided more than 20 postgraduate students for their research Dissertation. He is reviewer in various International peer review journals. He has got 4th best poster award, British Association for Crystal Growth/Irish Association for Crystal Growth Conference, Dublin, 2007.

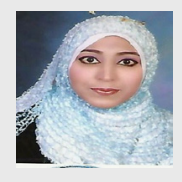

Dr. Eman Ali Ahmed, a Lecturer of Pharmacology, Suez Canal University and a senior researcher, Proteomics and Metabolomics Unit, Basic research, children's cancer hospital, Egypt. Eman get her PhD through a Joint program between Tokyo Univ. of Agriculture and Technology and Suez Canal Univ. Eman is specialist in pharmacology, reproductive biology, and metabolomics research. She has several publication in reputable journals https://scholar.google.com.eg/citations?user=X yTt7S4AAAAJ\&hl=en She is a member in several editorial board and as a reviewer also. She is a member in many national and international associations such as Japanese Society for Reproduction and Development (SRD), Japanese Society for Comparative Endocrinology, and International Association of University Women (EAUW).

Mrs. Yomna Abdelkarim Aboueisha, has completed B.Sc. Pharm from Faculty of Pharmacy, Suez Canal University, Ismailia, Egypt. She has attended various Seminars.

Cite this article: Aboueisha YA, Gad S, Khalil WF, Ahmed EA, GhorabMM. Effect of Ethyl Cellulose Content on Release Profile and Pharmacodynamics of Fenoprofen Microparticles. Indian $\mathrm{J}$ of Pharmaceutical Education and Research. 2019;53(3):446-56. 